\title{
Failed Gastric Pull up after Esophagectomy Managed by Colonic Interposition
}

\author{
Kapileshwer Vijay • Rajesh Godara • \\ Varunika Vijayvergia
}

Received: 11 August 2011 / Accepted: 21 June 2012 /Published online: 27 July 2012

(C) Association of Surgeons of India 2012

\begin{abstract}
A case of esophageal carcinoma underwent transthoracic esophagectomy with gastric pull-up. Postoperatively the patient had gastric conduit necrosis which manifested as biliary leak through the chest tube and was managed with colonic interposition. We present our unique experience of managing failed gastric pull-up with review of concerned literature.
\end{abstract}

Keywords Carcinoma esophagus · Gastric conduit necrosis · Colonic interposition

\section{Introduction}

After esophageal resection the selection and preparation of esophageal conduit is real challenge. The postoperative outcome and future quality of life are affected by viability and function of conduit. Esophageal conduit necrosis is an uncommon but disastrous complication of esophageal surgery carrying high morbidity and mortality. Careful selection of patients for surgery, proper planning and selection of conduit, and meticulous operative technique are the best preventive measure against conduit ischemia. Awareness of this rare entity in esophageal surgeries, high degree of suspicion, prompt diagnosis with early radiological imaging or endoscopy, and timely intervention can salvage the patient.

\section{K. Vijay $(\triangle) \cdot R$. Godara}

Department of Gastrointestinal Surgery and Liver Transplant,

Research \& Referral Army Hospital,

Delhi, India

e-mail: drkapileshwer@gmail.com

\section{Vijayvergia}

Department of Microbiology,

Research \& Referral Army Hospital,

Delhi, India

\section{Case Report}

A 65-year-old male patient, a known alcoholic and smoker, presented with the complaint of painless progressive dysphasia initially with solid and then progressed for liquids of 6 months' duration, associated with unquantified weight loss of 3 months' duration. His initial evaluation with esophagogastroscopy showed an ulceroproliferative growth at $26 \mathrm{~cm}$ from incisors, extending $3 \mathrm{~cm}$ in craniocaudal dimension. Biopsy was taken that proved well-differentiated squamous cell carcinoma. Contrast-enhanced CT scan of the chest and abdomen showed growth in the mid-esophagus just distal to the carina extending $4 \mathrm{~cm}$ in craniocaudal dimension with preserved fat plane with bronchi and aorta. No significant lymphadenopathy was observed.

The patient underwent transthoracic esophagectomy with two-field lymph node dissection. Gastric conduit was prepared on the right gastroepiploic arcade and end-to-end cervical esophagogastric anastomosis with pyloromyotomy was done; a bilateral intercostal drain and a negative suction drain in the neck were placed. Immediate postoperative recovery was normal. On the fourth postoperative day, the patient started draining bilious drainage in the right intercostal drain though neck wound was well healing with no evidence of sepsis/mediastinitis. As the patient had isolated bilious leak in drain, we had a suspicion of contained leak from the staple line of gastric conduit. The patient was taken up for exploration; intraoperatively we found necrosis at the tip of gastric conduit with the healthy staple line (Fig. 1). Gastric conduit was taken down to the abdomen; cervical esophagostomy and decompressing gastrostomy was done which was later used for feeding purpose.

Postoperative recovery was smooth. Meanwhile, histopathological examination confirmed well-differentiated squamous cell carcinoma (pT3N0M0, stage IIA). After 


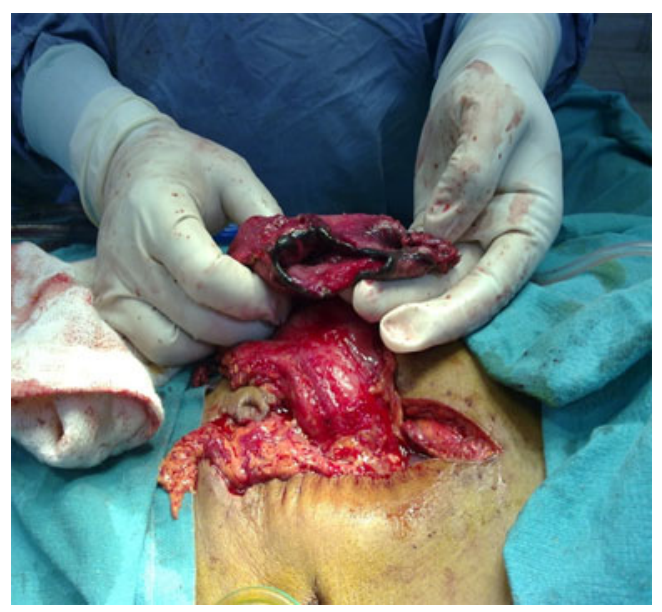

Fig. 1 Intra op photograph showing gastric conduit fundic part necrosed

wound healing, the patient was subjected on adjuvant chemoradiotherapy as per the institution-based protocol. After 3 months the patient was worked up to rule out any metastatic or recurrent disease with positron emission tomography with contrast-enhanced CT. As the stomach could not be used, we planned colonic interposition. Colonoscopy and mesenteric angiography were done to assess the colon and its vascularity. Isoperistaltic left colic graft was harvested based on the ascending branch of the left colic artery with substernal colonic interposition (Fig. 2). Cervical esophagocolic anastomosis was done in end-to-end fashion followed by end-to-side cologastric and end-to-end colocolic anastomosis with feeding jejunostomy. Postoperative recovery was normal, and on the fifth day the dye study showed smooth transit of dye (Fig. 3). The patient was discharged on the seventh postoperative day with normal feeding. On 16-month follow-up, the patient gained $6 \mathrm{~kg}$ weight with good quality of life and free from malignancy.

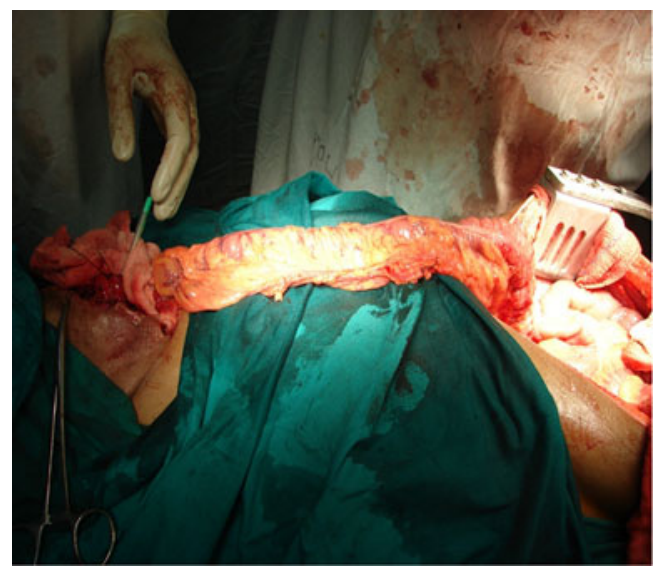

Fig. 2 photograph showing colonic conduit based on ascending branch of left colic artery

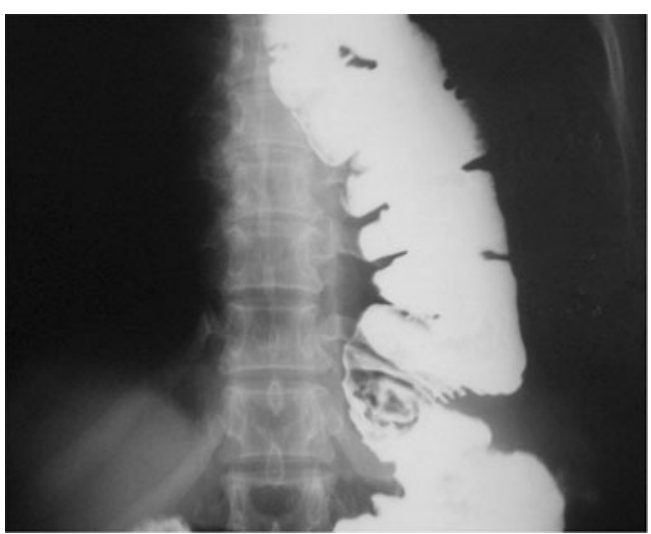

Fig. 3 Gastrograffin study showing smooth passage of contrast through colonic conduit

\section{Discussion}

Esophagectomy is the only curative treatment for resectable esophageal cancer. Reconstruction of the gastrointestinal tract is most commonly performed with a gastric pull-up and cervical esophagogastrostomy [1]. The viability and function of the esophageal conduit is most important predictor of postoperative outcome and quality of life. Esophageal conduit options are limited to stomach, colon, and jejunum, and options may be further limited by previous surgeries and coexisting disease. Esophageal cancer has traditionally been associated with poor surgical outcomes resulting from a wide spectrum of complications [2]. Ischemia of the gastric conduit is an uncommon but disastrous complication that even can lead to death $[3,4]$. The clinical range of conduit is broad and includes subclinical cases that resolve spontaneously, may manifest as leak, stricture, or frank necrosis. Fortunately, this complication is uncommon, with an incidence of $0.5-10 \%$ [5]. The pathogenesis of gastric conduit ischemia is uncertain, but there is a general consensus that it seems from critical ischemia caused by

Table 1 Endoscopic classification of Gastric conduit failure

\begin{tabular}{|c|c|c|}
\hline Type & Clinical Picture & Management \\
\hline \multicolumn{3}{|l|}{ I } \\
\hline $\begin{array}{l}\text { Simple } \\
\text { Anastomotic } \\
\text { Leak }\end{array}$ & $\begin{array}{l}\text { Early }- \text { minimal } \\
\text { impact Late - } \\
\text { Mediastinitis/ sepsis }\end{array}$ & $\begin{array}{l}\text { Conservative NBM } \\
\text { Prolonged jejunal } \\
\text { feeding }\end{array}$ \\
\hline \multicolumn{3}{|l|}{ II } \\
\hline $\begin{array}{l}\text { Conduit Tip } \\
\text { Necrosis }\end{array}$ & $\begin{array}{l}\text { Severe Mediastinitis } \\
\text { Systemic Sepsis }\end{array}$ & $\begin{array}{l}\text { Emergency Thoracotomy } \\
\text { Re-fashioning of Conduit } \\
\text { And Re-anastomosis }\end{array}$ \\
\hline \multicolumn{3}{|l|}{ III } \\
\hline $\begin{array}{l}\text { Complete } \\
\text { Conduit } \\
\text { Ischaemia }\end{array}$ & $\begin{array}{l}\text { Severe Sepsis Multiple } \\
\text { Organ Dysfunction } \\
\text { Syndrome }\end{array}$ & $\begin{array}{l}\text { Thoracotomy Resection } \\
\text { of Ischaemic Conduit } \\
\text { Temporary } \\
\text { Oesophagostomy And } \\
\text { Feeding Gastrostomy }\end{array}$ \\
\hline
\end{tabular}


impaired oxygen delivery to the distal gastric conduit used to fashion the anastomosis. Risk factors for gastric conduit necrosis include using improper technique in the creation or handling of the stomach tube, external beam irradiation, low perioperative cardiac output, postoperative hypotension, previous upper abdominal surgery, underlying gastric ulcer disease, twisting the stomach conduit as it passes up into the mediastinum, and a tight restrictive hiatus [6]. Most risk factors can be avoided by careful technique of mobilization of stomach, handing and formation of gastric conduit. Iannettoni and colleagues have proposed that routine use of tacking suture to anchor the tip of the stomach tube to the prevertebral fascia during transhiatal esophagectomy dramatically increases the risk of gastric tube tip necrosis [7]. The clinical presentation of ischemia depends on its extent and on the location of the esophageal anastomosis. Once the diagnosis of anastomotic leak is made, the possibility of gastric conduit necrosis should be ruled out, especially if the leak is large or occurs unusually early after initial surgery. Ischemia should also be suspected in any patient whose anastomotic leak is thought to be well drained (especially cervical leaks) but who still remain febrile and toxic for longer than $24 \mathrm{~h}$. Ischemia should always be suspected in patients who have continued "coffee ground" nasogastric aspirate, especially when associated with otherwise unexplained acidosis, leucocytosis, high-grade fevers, and respiratory failure [5]. CT scan is a noninvasive way to identify an ischemic conduit or an anastomotic breakdown, but it has high-false negative rate. Three distinct categories of surgical gastric conduit failure (GCF) were described by Veeramootoo and colleague on endoscopy (Table 1) [8].

Ultimate diagnosis remains on the high index of clinical suspicion, contrast imaging, endoscopy, and direct inspection. Mild cases of ischemia manifesting as anastomotic leak can be managed with drainage through neck incision. However, full-thickness necrosis is a disastrous complication that often requires resection of necrotic bowel, brought down the gut to abdomen, cervical esophagostomy, and feeding access through feeding gastrostomy or jejunostomy. Mortality of this complication has been reported to be as high as $90 \%$ if not managed on time.

There are no modalities that can reverse ischemia once it occurs. Hence, prevention is the best modality to treat graft ischemia. There is no role of anticoagulants, vasodilators, or steroids for the treatment of graft ischemia. Various methods to prevent this complication have been described - meticulous dissection, surgical technique, maintenance of cardiopulmonary and nutrition status, two-stage resection and reconstruction, wide cross-sectional area of esophagogastric anastomosis, vascular augmentation if needed, etc.
As our patient did not show any sign of sepsis, toxemia, or mediastinitis, we had clinical suspicion of contained leak from the staple line but our patient had fundic necrosis of gastric conduit. This occurs after $72 \mathrm{~h}$ which is ideal time for necrosis to develop due to vascular compromise. We were not sure about vascularity of gastric conduit, and hence conduit was brought back to the abdomen and partial gastrectomy with decompressive gastrostomy was done. Subsequently, restoration was done with colonic interposition.

In conclusion, in case of bile leak from the chest tube without local sign of leak in the neck or clinical sign of sepsis, mediastinitis could be manifestation of gastric conduit necrosis. Early intervention can salvage the patient. Out of three common esophageal replacement conduits available, the stomach has the lowest reported incidence of ischemia followed by the jejunum and colon. Intraoperative uses of handheld Doppler can minimize the incidence of graft ischemia and related complications. However, their routine use is not yet recommended. The knowledge of incidence, risk factors, diagnosis, prompt intervention, and prevention of conduit-related complication is key for understanding esophageal surgery.

\section{References}

1. Hagen JA, Demeester SR, Peters JH, Chandrasoma P, Demeester TR (2001) Curative resection of esophageal adenocarcinoma: analysis of 100 en bloc esophagectomies. Ann Surg 234:520-530

2. Hulscher JB, Tijssen JG, Obertop H, van Lanschot JJ (2001) Transthoracic versus transhiatal resection for carcinoma of the esophagus: a meta-analysis. Ann Thorac Surg 72:306-313

3. Briel JW, Tamhankar AP, Hagen JA, DeMeester SR, Johansson J, Choustoulakis E, Peters JH, Bremner CG, DeMeester TR (2004) Prevalence and risk factors for ischemia, leak, and stricture of esophageal anastomosis: gastric pull-up versus colon interposition. J Am Coll Surg 198:536-541

4. Urschel JD (1995) Esophagogastrostomy anastomotic leaks complicating esophagectomy: a review. Am J Surg 169:634-640

5. Oezcelik A, Banki F, Ayazi S, Abate E, Zehetner J, Sohn HJ et al (2010) Detection of gastric conduit ischemia or anastomotic breakdown after cervical esophagogastrostomy: the use of computed tomography scan versus early endoscopy. Surg Endosc 24:1948-1951

6. Wormuth JK, Heitmiller RF (2006) Esophageal conduit necrosis. Thorac Surg Clin 16:11-22

7. Iannettoni MD, Whyte RI, Orringer MB (1995) Catastrophic complications of the cervical esophagogastric anastomosis. J Thorac Cardiovasc Surg 110:1493-1500

8. Veeramootoo D, Parameswaran R, Krishnadas R, Froeschle P, Cooper M, Berrisford RG et al (2009) Classification and early recognition of gastric conduit failure after minimally invasive esophagectomy. Surg Endosc 23:2110-2116 